\title{
Optimising tear replacement rheology in canine keratoconjunctivitis sicca
}

\begin{abstract}
Dry eye is a substantial problem in a large number of human and canine patients. Numerous laboratory models for tear deficiency exist using genetically predisposed rodent models, animals treated with topical anti-muscarinics, or those kept in environments with increased air flow to produce the ocular surface changes seen in human patients. Canine keratoconjunctivitis sicca, seen in many thousands of dogs kept as companion animals, can provide a valuable spontaneous model for testing tear replacement medications that might better model disease in human patients, existing as it does in an outbred population that live in the same environments as their owners. Here the development of a crosslinked hyaluronic acid topical drop is described together with the results of trials on dogs with spontaneous keratoconjunctivitis sicca. Although hyaluronic acid in its native form in tear replacement drops shows a Newtonian rheology, the crosslinked product described here behaves in a non-Newtonian manner, with the same shear thinning shown by the tear film itself. The crosslinked product thus shows itself as a potentially valuable tear replacement medication for the human dry eye population as well as for dogs with the
\end{abstract} same condition.

Eye (2018) 32, 195-199; doi:10.1038/eye.2017.272; published online 5 January 2018

\section{Introduction}

It is a tough life being a tear drop. One moment you are adrift in the middle of a wide open cornea, clinging onto the ocular surface for grim death. Having as high a viscosity as possible in
DL Williams

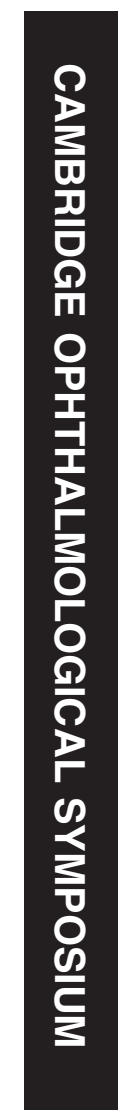

this situation is vital to avoid simply running downwards into the tear lake inferiorly. And then the next moment, before you know it and as if without warning, the eyelid comes sweeping down and immediately you have to lose all that viscosity and become as fluid as possible, to avoid damage to the epithelial cells as the blink occurs. A drop of water increases its viscosity very slightly as it is moved. It has what we term Newtonian fluid dynamics as it was Sir Isaac Newton who first showed that the stresses arising from the fluid flow in a conventional fluid are proportional to the local rate of change of its deformation over time. The forces resulting from fluid flow are proportional to the rates of change of the fluid's velocity vector. As he says in his Principia Mathematica of 1687 'The resistance which arises from the lack of slipperiness originating in a fluid - other things being equal - is proportional to the velocity by which the parts of the fluid are being separated from each other'. ${ }^{1}$ Newton's law of viscosity states that the shear stress on a fluid $\tau$ is equal to the shear rate $\gamma$ multiplied by a proportionality constant QUOTE the viscosity of the fluid. However, biological fluids such as blood, ${ }^{2}$ synovial fluid, ${ }^{3}$ and tears exhibit shear thinning, where their viscosity is not constant, but reduces with shear rate. This is related to the structural reorganisation of irregular moieties as velocity changes. In blood the interactions between erythrocytes are key in this behaviour whereas in synovial fluid it is hyaluronic acid existing as long chain anisotropic molecules that change the rheology of the fluid. ${ }^{4}$

If it is tricky being a tear drop, it is equally vexatious being a designer of a tear replacement drop. The very fact that we have so many from which to choose, carboxymethylcellulose, hydroxymethylcellulose, carbomer gel, hyaluronic acid, ${ }^{5}$ propylene glycol/ hydroxypropyl-guar, ${ }^{6}$ and lipid emulsion ${ }^{7}$ among artificial lacrimomimetics ${ }^{8}$ in products
Department of Veterinary Medicine, University of Cambridge, Cambridge, UK

Correspondence:

DL Williams, Department of Veterinary Medicine, University of Cambridge, Madingley Road, Cambridge CB3 OES, UK Tel: 012233376 21; Fax: 01223232977. E-mail: dlw33@cam.ac.uk

Received: 25 September 2017

Accepted: 8 October 2017

Published online:

5 January 2018 
ranging through Actimist, Advance Eye Relief, Akorn, Akwa, Blink, Clarymist, Clear Eyes, Freshkote, GenTeal, Hylogel, Isopto, Just Tears, Lacril, Lacrisert, Liposic, Lubrifresh, Murine Tears, Natural Balance, Nature's Tears, Nutratear, Oasis Tears, Paralube, Refresh, Rohto Hydra, Systane, Soothe, Tearisol, Tears Again, Tears Natural, Thera Tears, Ultra Tears, Visco Tears, and Vizulize Dry Eye Mist and even good old fashioned Lacrilube with products such as lanolin from sheep wool, ${ }^{9}$ not to forget of saliva in submandibular gland transplantation in human patients ${ }^{10}$ or parotid duct transposition in the $\mathrm{dog}^{11}$ suggests that none is $100 \%$ effective in every patient. And neither should we expect them to be, for the tear film is not one component alone but a number. The tear film is widely recognised now to be a good deal more complicated that the trilaminar structure first proposed by Wolff in $1946 .{ }^{12}$ Mucins both attach to the conjunctival and corneal epithelium and float free in the tear film giving a more graded viscosity in the tear film, and a thicker tear layer to boot, as first demonstrated by Prydal and Campbell back in $1992 .{ }^{13}$ On top of this graded mucin/aqueous mix lies a layer of lipid that itself has complex rheological properties. ${ }^{14}$ The fact that we are dealing with several different structures, the epithelium and its glycocalyx, the mucin/aqueous gradation, and the lipid layer giving surface protection, means that dealing with the tear film as one single entity is bound to fail, both from a conceptual basis and at a practical level. How in one drop can we seek to replicate the complex structure and function of the tear film? And what model should we use to determine if we have got it right?

\section{Models of the tear film in health and disease}

Laboratory animal models of dry eye are numerous and varied. There are rodent strains with inherited predisposition to immunologically mediated dry eye similar to Sjogren's syndrome-the MRL mouse in particular. ${ }^{15}$ Pharmacological intervention using topical atropine or benzalkonium chloride has been widely used with markedly varying results even between different rodent strains in the case of benzalkonium chloride. ${ }^{16}$ The molecule causes corneal epithelial disruption, stromal neovascularisation, and infiltration of inflammatory cells that mimic those changes caused in dry eye but not through the same mechanisms. The muscarinic antagonist atropine sulphate does cause tear reduction in several laboratory animal models that have then been used to evaluate the efficacy of topical tear replacement. ${ }^{17}$ The same can be achieved by surgical removal of the lacrimal gland $^{18}$ but not employing denervation by injection of the toxin saponin. ${ }^{19}$ All of these models however cause a panoply of signs that may be linked to the cause of the damage to the eye rather than to ocular surface dryness itself as shown by the toxic denervation mode ${ }^{18}$ that does not reduce tear production as measured by the phenol thread test. Reducing tear production with atropine or scopolamine followed by exposure to a desiccating airflow for 5 to 10 days provokes the type of ocular surface pathology seen in naturally occurring dry eye and has been a valuable model for dissecting the processes happening in the development of keratoconjunctivitis sicca. ${ }^{20}$ However, it has the disadvantage that it is very far from the spontaneous disease in human patients.

Spontaneous keratoconjunctivitis sicca seen in dogs kept as companion animals however has the advantage of being similar in pathogenesis to human dry eye. ${ }^{21}$ The condition occurs through autoimmune destruction of the lacrimal gland similar to that occurring in Sjogren's syndrome in the human patient and is particularly valuable in that it exists in an animal larger than the laboratory rodents and rabbits otherwise used (Figure 1a). It does have the disadvantage of being less readily controlled in its time and severity of onset than a rodent model $^{22}$ and the fact that it occurs on a more varied
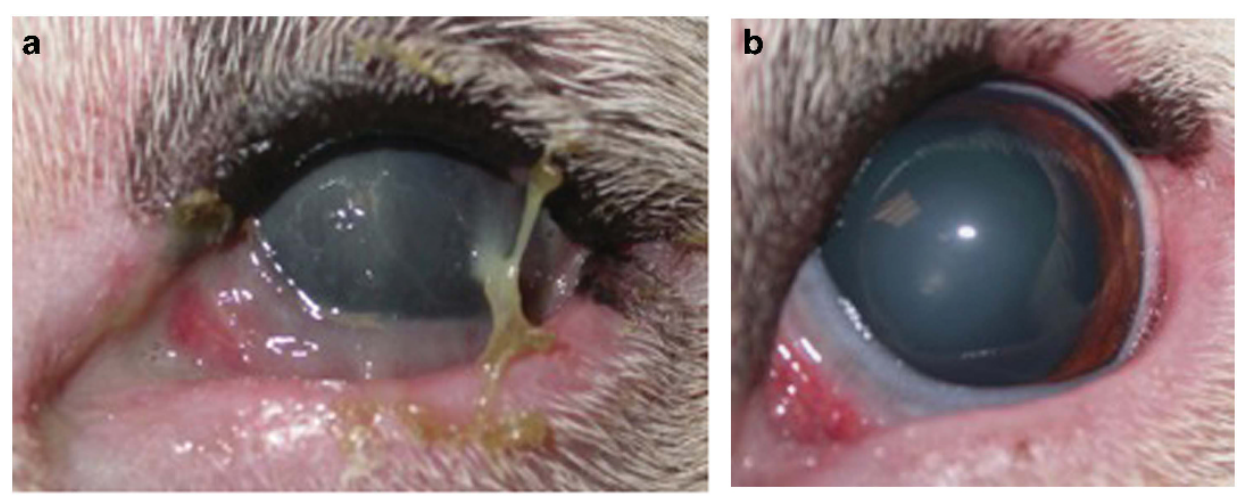

Figure 1 The eye of a 5-year-old English bull terrier with corneal oedema and ulceration, conjunctival hyperaemia, and ocular surface discharge classic of canine keratoconunctivitis sicca before treatment (a) and after 3 weeks of topical CMHA-S treatment three times daily (b). 
genetic background could be seen as a disadvantage in that it complicates matters by bringing into play a number of uncontrollable variables. On the other hand, this outbred genetic background could be seen as advantageous given that it more closely models the real world of human patients where disease occurs against different genetic and environmental backgrounds. The ocular disease in canine keratoconjunctivitis sicca is similar to human dry eye, although in many cases more severe often with compete absence of tear production to warrant consideration as an example of translation medicine in a 'one health' scenario. ${ }^{23}$ Dry eye occurs very commonly in dogs kept as companion animals. The first survey of canine keratoconjunctivitis sicca was undertaken by Professor Lloyd Helper, a key player at the beginning of modern veterinary ophthalmology, who noted only $0.4 \%$ of the canine population to be affected with a deficiency in tear production in 1976. ${ }^{24}$ After 20 years, Dr Renee Kaswan, a leader in canine dry eye research, reported a prevalence of up to $35 \%$ in the patients she surveyed. ${ }^{25}$ The truth is that the number of animals affected is probably somewhere in between these two figures. Research we undertook in Cambridge to measure the Schirmer tear test (STT) in 1000 dogs demonstrated levels of tear production lower than $15 \mathrm{~mm}$ of tear strip wetting in $1 \mathrm{~min}$ in 131 dogs giving a prevalence of $13 \%$. In a recent survey of the cases seen in the clinic of the Queen's Veterinary School Hospital, University of Cambridge, 181 of the last thousand cases seen were affected by keratoconjunctivitis sicca. ${ }^{26}$ This high prevalence of the condition means that a population for evaluation of new products to be used in canine dry eye can readily be accessed.

\section{Developing a non-Newtonian tear replacement}

We noted above that synovial fluid is non-Newtonianthe lubricating liquid in the hip joint, to take one example, needs to exhibit shear thinning to be able to cope with standing still and then with moving rapidly. I often ask owners of dogs with dry eye whether they have ever considered the eye to be like a hip joint. Few, if any, have! Yet, as I explain to them, the eye is, in effect, a ball and socket joint. The sclera is like cartilage, the conjunctiva like synovial membrane, and tears are like joint fluid. Except that of course it is not quite so simple: such a viscous covering of the ocular surface would blur our vision quite inappropriately. We have seen that tears do behave in a non-Newtonian manner but in a very thin layer across the ocular surface, comprising a volume estimated to be $\sim 3 \mu \mathrm{l} .{ }^{27} \mathrm{~A}$ drop of a lacrimomimetic fluid from an ophthalmic dropper bottle is between 25 and $70 \mu \mathrm{l} .{ }^{28}$ Whichever product we use, a single drop will dramatically overload the tear film. A fluid behaving

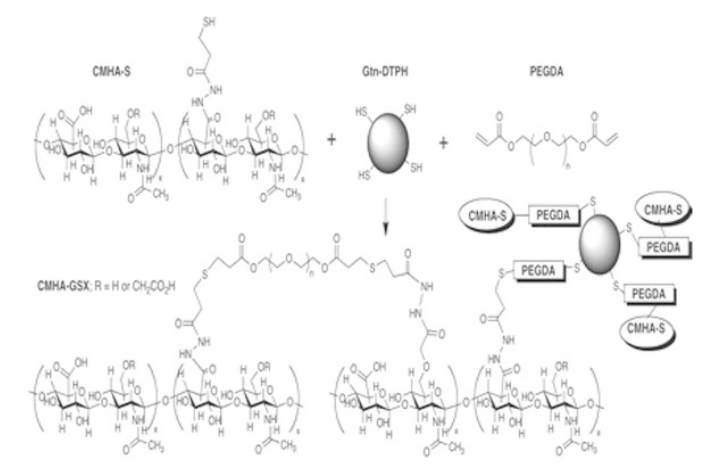

Figure 2 Chemical reactions used in formulation of crosslinked carboxymethyl hyaluronic acid (taken from Williams and $\left.\mathrm{Mann}^{33}\right)$.

with a Newtonian rheology will provide some degree of ocular surface lubrication, but require a sizeable volume of product blurring vision and also needing frequent application. Perhaps a product behaving on the ocular surface in a non-Newtonian manner can provide a longlasting lubricant covering for the ocular surface, with a prolonged residence time although whereas existing as a thin pauci-molecular layer

The plethora of reports on topical treatments for dry eye are often contradictory. To take one example, standard hyaluronic acid tear replacement drops have been shown by some researchers to have a beneficial protective effect on corneal epithelium in patient studies ${ }^{29}$ and in laboratory studies using chick corneal explants, ${ }^{30}$ whereas others have shown no effect. ${ }^{31}$ Yet, these papers have used $0.3 \%$ and $0.1 \%$ hyaluronic acid, respectively, with neither report documenting the molecular weight of the molecule used in either study. If the rheology of the medication is a key factor differing molecular weights may be key. Hyaluronic acid molecules in the synovial fluid of young healthy human knee joints have been shown to have a molecular weight of between 2.5 and 7 MDa. ${ }^{32}$ Their rheological behaviour is non-Newtonian with shear thinning as discussed above. ${ }^{4}$ The hyaluronic acid molecules in standard tear replacement drops, on the other hand, are much smaller with a molecular weight of 1.5-1.8 MDa.(Dr Brenda Mann, University of Utah Bioengineering Department, personal communication, 2017) The rheological behaviour of such hyaluronic acid products generally containing relatively short molecules at relatively low concentrations is for the most part Newtonian with an increase in viscosity with shear rate. ${ }^{33}$ Research at the University of Utah Department of Bioengineering has investigated crosslinking of hyaluronic acid to create molecules exhibiting shear thinning and thus forming a valuable addition to the panoply of tear replacement medications. To crosslink the molecules a reactive group is first introduced into the 


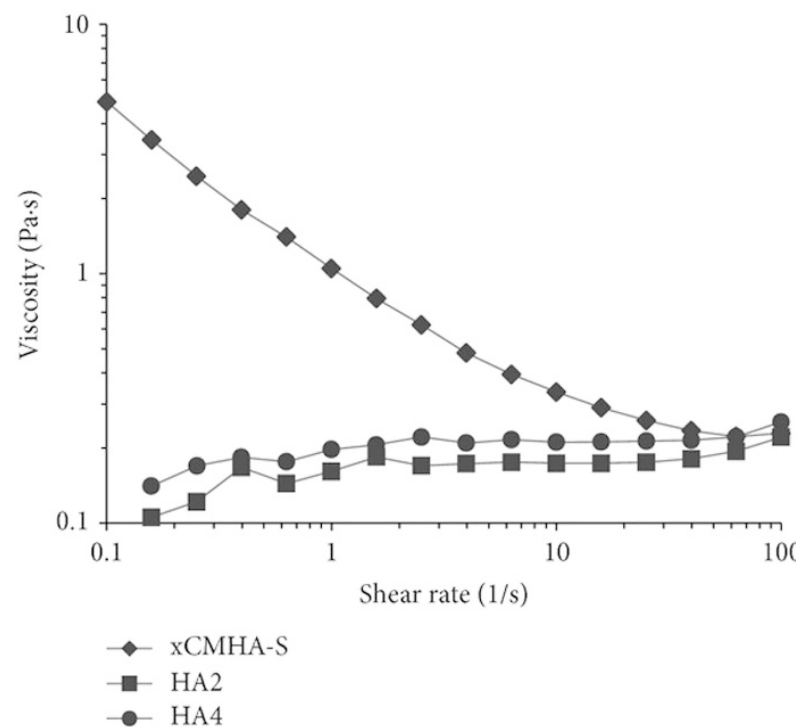

Figure 3 Change in viscosity with differing shear rates of conventional hyaluronic acid and crosslinked thiolated carboxymethyl hyaluronic acid showing classical shear thinning in the crosslinked product (taken from Williams and Mann $\left.^{33}\right)$.

molecule by carboxylating hydroxyl groups. Next, a hydrazide is coupled to the carboxyl groups producing free thiols that can then be crosslinked, covalently joining the hyaluronic acid molecules (Figure 2). It is difficult to give a precise molecular weight for this crosslinked thiolated carboxymethyl hyaluronic acid (CMHA-S) as the carboxylation is random and a range of molecules are thus produced. But what can be evaluated is the rheology of the resulting gel. As shown in Figure 3 non-crosslinked hyaluronic acid has a low viscosity that increases with elevated shear rate. The crosslinked product, on the other hand, has a much higher viscosity at low shear rates, dropping substantially as the shear rate increases-a nonNewtonian rheology that is just what the ocular surface needs as we noted above.

\section{Testing tear replacement products in the spontaneous canine model}

In a randomised, double-masked, controlled study, the beneficial effects of the novel topical crosslinked carboxymethyl hyaluronic acid product on canine eyes with aqueous tear deficiency were compared with those of a standard hyaluronic acid tear replacement drop. In this research on 30 dogs affected by keratoconjunctivitis sicca, ${ }^{34}$ conjunctival hyperaemia, adnexal discharge, and ocular discomfort were all reduced significantly more by the crosslinked hyaluronic acid product that by the standard tear replacement drop. Indeed, the product not only ameliorates canine dry eye but, as we have recently shown in a group of dogs kept as companion animals and effected with stromal corneal ulceration, the crosslinked product also significantly increases the speed of corneal ulcer healing. ${ }^{35}$ Whether this relates to the rheological behaviour of the product and its prolonged ocular surface residence time is at present unclear; it may be that hyaluronic acid itself, binding to the CD44 molecule on the cell surface of corneal epithelial cells, and potentially stromal keratococytes as well, increases their migration rate to heal the ulcer.

\section{Conclusion}

Producing a tear replacement drop that accurately replicates the non-Newtonian rheology of the normal tear film is not easy. Testing tear replacements drops on an animal model of human dry eye might also be said to be equally taxing. Here a crosslinked hyaluronic acid product is described, tested for beneficial effects on spontaneous dry eye in dogs kept as companion animals, thus showing the value of a lacrimomimetic agent exhibiting shear thinning and the advantages of using spontaneous dry eye in pet dogs as a model for evaluating tear replacement medication.

\section{Conflict of interest}

The author declares no conflict of interest.

\section{References}

1 Newton IS. Philosophiae Naturalis Principia Mathematica. Bk 2 Sect IX, 1687, Royal Society: London.

2 Baieth HE. Physical parameters of blood as a non newtonian fluid. Int J Biomed Sci 2008; 4: 323-329.

3 Hlavácek M. The thixotropic effect of the synovial fluid in squeeze-film lubrication of the human hip joint. Biorheology 2001; 38: 319-334.

4 Martin-Alarcon L, Schmidt TA. Rheological effects of macromolecular interactions in synovial fluid. Biorheology 2016; 53: 49-67.

5 Williams D, Middleton S, Fattahian H, Moridpour R. Comparison of hyaluronic acid-containing topical eye drops with carbomer-based topical ocular gel as a tear replacement in canine keratoconjunctivitis sicca: a prospective study in twenty five dogs. 2012Vet Res Forum 3: 229-232.

6 Christensen MT, Cohen S, Rinehart J, Akers F, Pemberton B, Bloomenstein $\mathrm{M}$ et al. Clinical evaluation of an HP-guar gellable lubricant eye drop for the relief of dryness of the eye. Curr Eye Res 2004; 28: 55-62.

7 Scaffidi RC, Korb DR. Comparison of the efficacy of two lipid emulsion eyedrops in increasing tear film lipid layer thickness. Eye Contact Lens 2007; 33: 38-44.

8 Moshirfar M, Pierson K, Hanamaikai K, Santiago-Caban L, Muthappan V, Passi SF. Artificial tears potpourri: a literature review. Clin Ophthalmol 2014; 8: 1419-1433.

9 Green-Church KB, Butovich I, Willcox M, Borchman D, Paulsen F, Barabino $\mathrm{S}$ et al. The international workshop on 
meibomian gland dysfunction: report of the subcommittee on tear film lipids and lipid-protein interactions in health and disease. Inv Ophthalmol Vis Sci 2011; 52: 1979-1993.

10 Borrelli M, Schröder C, Dart JK, Collin JR, Sieg P, Cree IA et al. Long-term follow-up after submandibular gland transplantation in severe dry eyes secondary to cicatrizing conjunctivitis. Am J Ophthalmol 2010; 150: 894-904.

11 Rhodes M, Heinrich C, Featherstone H, Braus B, Manning S, Cripps PJ et al. Parotid duct transposition in dogs: a retrospective review of 92 eyes from 1999 to 2009. Vet Ophthalmol 2012; 15: 213-222.

12 Wolff E. The muco-cutaneous junction of the lid margin and the distribution of the tear fluid. Trans Ophthalmol Soc UK 1946; 66: 291.

13 Prydal JI, Campbell FW. Study of precorneal tear film thickness and structure by interferometry and confocal microscopy. Invest Ophthalmol Vis Sci 1992; 33: 1996-2005.

14 Rosenfeld L, Cerretani C, Leiske DL, Toney MF, Radke CJ, Fuller GG. Structural and rheological properties of meibomian lipid. Invest Ophthalmol Vis Sci 2013; 54: 2720-2732.

15 Donate A, Voigt A, Nguyen CQ. The value of animal models to study immunopathology of primary human Sjögren's syndrome symptoms. Expert Rev Clin Immunol 2014; 10: 469-481.

16 Yang Q, Zhang Y, Liu X, Wang N, Song Z, Wu K. A comparison of the effects of benzalkonium chloride on ocular surfaces between C57BL/6 and BALB/c mice. Int J Mol Sci 2017; 18: 509-513.

17 Burgalassi S, Panichi L, Chetoni P, Saettone MF, Boldrini E. Development of a simple dry eye model in the albino rabbit and evaluation of some tear substitutes. Ophthalmic Res 1999; 31: 229-235.

18 Meng ID, Barton ST, Mecum NE, Kurose M. Corneal sensitivity following lacrimal gland excision in the rat. Invest Ophthalmol Vis Sci 2015; 56: 3347-3354.

19 Aicher SA, Hermes SM, Hegarty DM. Denervation of the lacrimal gland leads to corneal hypoalgesia in a novel rat model of aqueous dry eye disease. Invest Ophthalmol Vis Sci 2015; 56: 6981.

20 Stern ME, Pflugfelder SC. What we have learned from animal models of dry eye?. Int Ophthalmol Clin 2017; 57: 109-118.

21 Kaswan RL, Salisbury MA, Ward DA. Spontaneous canine keratoconjunctivitis sicca. A useful model for human keratoconjunctivitis sicca: treatment with cyclosporine eye drops. Arch Ophthalmol 1989; 107: 1210-1216.
22 Williams DL. Immunopathogenesis of keratoconjunctivitis sicca in the dog. Vet Clin North Am Small Anim Pract 2008; 38 (2): 251-268.

23 Welburn S. One Health: the 21st century challenge. Vet Rec 2011; 168: 614-615.

24 Helper LC. Keratoconjunctivitis sicca in dogs. Trans Sect Ophthalmol Am Acad Ophthalmol Otolaryngol 1976; 81: 624-628.

25 Kaswan R, Pappas C Jr, Wall K, Hirsh SG. Survey of canine tear deficiency in veterinary practice. Adv Exp Med Biol 1998; 438: 931-939.

26 Williams DL. Ophthalmic disease in pedigree dogs: an ethical and welfare conundrum. AWSELVA J 2012; 16: 10-15.

27 Palakuru JR, Wang J, Aquavella JV. Effect of blinking on tear volume after instillation of midviscosity artificial tears. Am J Ophthalmol 2008; 146: 920-924.

28 Sklubalová Z, Zatloukal Z. Systematic study of factors affecting eye drop size and dosing variability. Pharmazie 2005; 60: 917-921.

29 Condon PI, McEwen CG, Wright M, Mackintosh G, Prescott RJ, McDonald C. Double blind, randomised, placebo controlled, crossover, multicentre study to determine the efficacy of a $0.1 \%(\mathrm{w} / \mathrm{v})$ sodium hyaluronate solution (Fermavisc) in the treatment of dry eye syndrome. Br J Ophthalmol 1999; 83: 1121-1124.

30 Wysenbeek YS, Loya N, Sira BI, Ophir I, Ben Shaul Y. The effect of sodium hyaluronate on corneal epithelium. Invest Ophthalmol Vis Sci 1988; 29: 194-199.

31 Nelson JD, Farris LR. Sodium hyaluronate and polyvinylalcohol artificial tears preparations. A comparison in patients with keratoconjunctivitis sicca. Arch Ophthalmol 1988; 106: 484-487.

32 Temple-Wong MM, Ren S, Quach P, Hansen BC, Chen AC, Hasegawa $\mathrm{A}$ et al. Hyaluronan concentration and size distribution in human knee synovial fluid: variations with age and cartilage degeneration. Arthritis Res Ther 2016; 18: 18.

33 Williams DL, Mann BK.. A crosslinked HA-based hydrogel ameliorates dry eye symptoms in dogs. Int J Biomater 2013; 2013: 460437.

34 Williams DL, Mann BK. Efficacy of a crosslinked hyaluronic acid-based hydrogel as a tear film supplement: a masked controlled study. PLOS ONE 2014; 9: e99766.

35 Williams DL, Wirostko BM, Gum G, Mann BK. Topical cross-linked HA-based hydrogel accelerates closure of corneal epithelial defects and repair of stromal ulceration in companion animals. Invest Ophthalmol Vis Sci 2017; 58: $4616-4622$. 